\title{
ANÁLISE DO CRESCIMENTO E DESENVOLVIMENTO DA MELISSA (Melissa officinalis L.) EM DIFERENTES NIIVEIS DE ADUBAÇÃO ORGÂNICA
}

\author{
Growth and Development Analysis of Melissa officinalis L. \\ Fertilized with Different Levels of Organic Matter
}

Tatiana Wolanski ${ }^{1}$

Ruy Inácio Neiva de Carvalho²

\section{Resumo}

O experimento visou determinar os efeitos da utilização de diferentes níveis de adubação orgânica sobre o crescimento e desenvolvimento de melissa. Foram utilizadas 400 plantas, distribuídas em delineamento experimental completamente casualisado, com cinco tratamentos $\left(0,25,50,75\right.$ e $100 \mathrm{~kg}$ de húmus $/ \mathrm{m}^{3} \mathrm{de}$ substrato), quatro repetições e vinte plantas por repetição. A pesquisa foi acompanhada por análises da altura das plantas e de sua biomassa até 133 dias. Após a colheita, as plantas frescas e posteriormente secas foram pesadas em balança de precisão. De acordo com os resultados obtidos no experimento foi possível concluir que o uso de húmus de minhoca influenciou no crescimento e no desenvolvimento das plantas, que apresentaram um crescimento inicial lento, até 19 dias do plantio, seguido de uma rápida resposta à adubação (19-64 dias após o plantio), voltando a apresentar um crescimento lento em altura após 64 dias do plantio. Dessa forma, concluiu-se que a altura atingida é o limite para a espécie estudada, porém ao mesmo tempo em que as plantas atingiram o limite, se ramificaram para os lados, apresentando maiorvolume em biomassa. Os diferentes níveis de adubação orgânica, quando comparados com a testemunha, apresentaram as melhores respostas tanto na altura das plantas quanto no peso das matérias fresca e seca, sendo o nível de $100 \mathrm{~kg}$ de húmus $/ \mathrm{m}^{3}$ o mais adequado. $\mathrm{O}$ cultivo de melissa fora de época em casa de vegetação apresentou viabilidade nos tratamentos que receberam diferentes níveis de adubação orgânica.

Palavras-chave: Húmus de minhoca; Plantas medicinais; Massa seca; Massa fresca; Colheita.

1 Estudante do Curso de Agronomia do Centro de Ciências Agrárias e Ambientais da Pontifícia Universidade Católica do Paraná. Rodovia BR376 km 14 CEP 80010/500 - São José dos Pinhais - PR. tatianawolanski@hotmail.com ou tatiwki@yahoo.com.br ou wolanski@bol.com.br

2 Engenheiro Agrônomo, Dr., Professor Adjunto I do Centro de Ciências Agrárias e Ambientais da Pontifícia Universidade Católica do Paraná. Rodovia BR376 km 14 CEP 83010/500 - São José dos Pinhais - PR. ruycarvalho@zipmail.com.br 


\section{Abstract}

This experiment aimed to evaluate the effects of different levels of organic fertilization in the growth and development of Melissa officinalis. The experimental design used was the completely randomized with five treatments $\left(0,25,50,75,100 \mathrm{~kg}\right.$ of worm coprolite $/ \mathrm{m}^{3}$ of substrate) and four replications, each one with 20 plants, totalizing 400 plants. The height and the fresh and dried biomass of plants were analyzed until 133 days. The organic fertilization with worm coprolite influenced the growth and development of plants mainly after 19 days. Independently of organic fertilization, after 64 days the plants presented a slow grow th in height, however the fresh and dried biomass were accumulated, indicating a lateral growth. The level of $100 \mathrm{Kg}$ of worm coprolite/ $\mathrm{m}^{3}$ of substrate resulted in an intense growth in height and in the best accumulation of fresh and dried biomass. The viability of Melissa officinalis cultivation in green house was possible only with the organic fertilization.

Keywords: Worm coprolite; Medicinal plants; Dried mass; Fresh mass; Harvest.

\section{Introdução}

As plantas medicinais e suas formas derivadas constituíram durante séculos a base da terapêutica. Segundo uma estimativa da Organização Mundial de Saúde (OMS), cerca de 80\% da população mundial recorre à medicina tradicional para satisfazer suas necessidades de cuidados primários de saúde (CORREA JUNIOR, 1998).

A Melissa officinalis é conhecida também como erva-cidreira, melissa romana ou chá da França. A melissa é uma planta originária do Sul da Europa (região mediterrânea) e Oriente Médio. É uma planta cultivada em vários países de clima subtropical e temperado, e encontrada em quase todo o Brasil, especialmente nos estados sulinos (CASTRO; CHEMALE , 1995).

Seguramente, o chá de melissa é um dos mais apreciados por todo o mundo (HORTA EM CASA, 2002). A parte com maior representatividade se encontra no sistema de folhas, que são utilizadas para medicamento e condimento, sendo essas colhidas no seu máximo de produção de massa verde e concentração de princípios ativos, que ocorre quando surgem os primeiros botões florais (CASTRO; CHEMALE, 1995). A concentração de princípios ativos na planta depende, naturalmente, do controle genético e dos estímulos proporcionados pelo meio, como, por exemplo, fatores climáticos, edáficos, exposições a microrganismos, insetos, outros herbívoros e poluentes. Os estímulos proporcionados pelo meio são normalmente caracterizados como situações de estresse, isto é, excesso ou deficiência de algum fator de produção para a planta. Dentre os fatores climáticos, o fotoperíodo (número de horas de luz por dia necessário para que uma planta possa florescer), a temperatura e o estresse hídrico podem determinar em certas espécies a época ideal de colheita em que poderá se obter uma maior quantidade de princípio ativo desejado. Existem vários grupos de princípios ativos como, por exemplo, os alcalóides, os óleos essenciais, os taninos, as saponinas, os glicosídios cardiotômicos e os flavonóides (GEOCITIES, 2002a).

As propriedades terapêuticas dessa planta são muitas: (a) digestiva: combate a fermentações no trato digestivo, agindo contra as náuseas; (b) relaxante: atua no tratamento da insônia, histeria e melancolia; (c) calmante: atua nas palpitações do coração; (d) problemas hepáticos e biliares; (e) alívio da dor de picadas de insetos e (f) irregularidades menstruais. Ao perfume se adiciona odor de limão, dando características refrescante e aquecedora (GEOCITIES, 2002a).

Nesta planta observa-se que as folhas são bem formadas e dispostas como andares (alternadas), sendo um par em cima do outro, sem modificação notável entre folhas que estão em baixo e as de cima (CANALVIP, 2002). É uma planta perene, herbácea, com caule muito ramificado, tenro, quadrangular, ereto ou mais ou menos prostrado, piloso e aromático (CASTRO; CHEMALE, 1995).

As folhas são grandes, ovais, pecioladas, serrilhadas, com nervuras salientes e reticuladas na face inferior (CORREA JUNIOR et al., 1994). Suas flores são pequenas, hermafroditas, zigomorfas, diclamídeas e pentâmeras (CASTRO; CHEMALE, 1995). O fruto tem quatro cerdas marcadas e as sementes são de cor parda escura e brilhante (CORREA JUNIOR et al., 1994).

A obtenção de mudas da melissa pode ser feita por sementes, divisão de touceiras ou por estaquia de galhos (SCHARNIK, 2001). 
A planta prefere os climas temperados para quentes. Necessita receber bastante luz solar, mas não tolera o calor excessivo e se desenvolve bem em locais parcialmente sombreados durante o dia. A melissa prefere solos férteis e ricos em matéria orgânica, com boa umidade, porém drenados (CORREA JUNIOR et al., 1994).

Nesse sentido, o desenvolvimento de plantas medicinais está diretamente relacionado à disponibilidade de nutrientes no solo, uma vez que o adubo orgânico promove melhores condições físicas, químicas e biológicas, contribuindo para a manutenção da fertilidade biológica. A utilização da adubação orgânica (húmus de minhoca) apresenta-se como uma opção de extrema curiosidade e importância para o cultivo de plantas medicinais. Por ser muito rico em nutrientes, o adubo orgânico atende às exigências das plantas, que carecem de solos férteis e ricos em nutrientes.

Segundo Lopes et al. (1975), a adubação orgânica, além de fornecer nutrientes às plantas, proporciona melhoria na estrutura física do solo, aumenta a retenção de água, diminui perdas por erosão, favorece o controle biológico devido a maior população microbiana e melhora a capacidade tampão do solo.

De acordo com Primavesi (1982), a adubação orgânica aumenta a capacidade de troca catiônica, eleva o pH e com isso reduz o teor de alumínio trocável, aumentando a disponibilidade de nutrientes aplicados por meio dos fertilizantes minerais.

Haworth e Cleaver (1967) mencionaram que a adubação orgânica garante produtividade semelhante ou maior do que a obtida com os adubos minerais.

O húmus, por se tratar de um adubo orgânico, traz vários benefícios para o solo, dentre os quais podemos destacar: diminuição da quantidade de adubo químico, portanto menores gastos com este produto; melhoria considerável da porosidade e da aeração do solo, aumentando a capacidade de captação de nutrientes pelas plantas; é um produto natural, que não degrada o meio ambiente; pode ser empregado em todo tipo de cultura e promove no solo uma maior retenção da umidade, impedindo que as chuvas levem os nutrientes do solo (lixiviação) (PEREIRA, 1997).

A matéria orgânica é imprescindível para enriquecer a biologia do solo, uma vez que ali- menta a cadeia de microrganismos, sem os quais as plantas tornam-se suscetíveis aos ataques dos nematóides. A matéria orgânica recompõe níveis básicos de CTC (capacidade de troca catiônica), aumenta a fertilidade do solo e, além de armazenar microelementos vitais, favorece a neutralização daqueles prejudiciais às plantas, como os que promovem a acidez no solo, em solos pobres (argilosos, plásticos). O húmus e a minhoca funcionam como catalisadores para a vida do solo, acelerando os processos de resgate biológico, aumentando a retenção de umidade e promovendo uma liberação gradativa dos nutrientes (PEREIRA, 1997).

O húmus de minhoca é um material rico em matéria orgânica e sais minerais facilmente absorvidos pelas plantas. É um produto orgânico estável, uniforme, inodoro, de coloração escura, cujos grânulos lembram pó de café. É um produto que não tem cheiro, não atrai moscas e principalmente não prejudica as plantas (PEREIRA, 1997).

Ao melhorar o desempenho fitossanitário das plantas de cultura, o húmus contribui, decisivamente, para a eliminação ou redução drástica da necessidade do uso de agrotóxicos, evitando os poluentes metálicos que se depositam nos alimentos e nas águas que a população consome (GEOCITIES, 2002b).

Segundo Correa Junior et al. (1994), o húmus de minhoca ou vermicomposto não é largamente utilizado devido sua pouca divulgação, porém representa uma opção interessante, pois é um adubo orgânico muito rico em nutrientes.

Dessa forma, pode-se observar a grande importância do estudo da viabilidade do cultivo de espécies de plantas medicinais fora de sua época de cultivo em casa de vegetação e da utilização do húmus de minhoca, levando-se em consideração não apenas o fator econômico, mas também 0 objetivo a que se destina.

Os objetivos do presente experimento foram avaliar a influência de diferentes níveis de adubação orgânica (húmus de minhoca) no crescimento e no desenvolvimento da biomassa de melissa, estudar a viabilidade do cultivo de melissa em casa de vegetação, desenvolver curvas de crescimento de melissa, visando estabelecer subsídios para a recomendação dessa adubação orgânica no cultivo e comercialização desta espécie. 


\section{Materiais e métodos}

O experimento foi conduzido na casa de vegetação do Câmpus São José dos Pinhais da Pontifícia Universidade Católica do Paraná, localizada no município de São José dos Pinhais, PR.

As plantas foram distribuídas em delineamento experimental completamente casualisado com cinco tratamentos com diferentes níveis de húmus de minhoca (0, 25, 50, 75 e 100 kg de húmus $/ \mathrm{m}^{3}$ de terra preta), quatro repetições por tratamento e vinte plantas por repetição, totalizando 400 plantas.

A primeira variável analisada foi a altura média das plantas, em que cinco delas, em cada repetição por tratamento, foram escolhidas ao acaso, e marcadas com estacas para a avaliação aos 19, 36, 64 e 133 dias após a instalação do experimento.

A segunda variável analisada foi a avaliação da biomassa de melissa aos 133 dias após a instalação do experimento. Foram escolhidas ao acaso três plantas de cada repetição por tratamento e realizada a colheita da parte aérea das plantas rente ao solo. Também foram escolhidas ao acaso quatro plantas de cada repetição e realizada a co- lheita da parte aérea a $6 \mathrm{~cm}$ do solo, bem como a coleta de amostras do solo de cada tratamento, num total de 5 amostras, para posterior avaliação.

Efetuou-se a retirada das plantas daninhas, principais concorrentes para as plantas, com relação a fatores como água, luz e nutrientes.

A avaliação do experimento foi feita pela pesagem das plantas, utilizando-se balança de precisão e secagem das plantas a $35^{\circ} \mathrm{C}$ por 6 horas e posteriormente a $70^{\circ} \mathrm{C}$ por 48 horas, utilizando-se estufa de secagem.

Calculou-se a massa seca das plantas com umidade de $0 \%$ e com umidade corrigida a $12 \%$, simulando a massa seca do material comencializado.

Os dados coletados foram submetidos à análise de variância e teste " $F$ ", sendo que as médias de tratamento com diferenças significativas pelo teste "F" foram submetidas à análise de regressão.

\section{Resultados}

Conforme os dados observados nos gráficos 1 e 2, houve uma diferença significativa no que se refere à altura das plantas.

\section{GRÁFICO 1 - Altura das plantas de M elissa officinalis adubadas com 0 e $25 \mathrm{~kg}$ de húmus $/ \mathrm{m}^{3}$ de substrato. \\ Graph 1 - Height of Melissa officinalis, fertilized with 0 and $25 \mathrm{~kg}$ of worm coprolite $/ \mathrm{m}^{3}$ of substratum.}

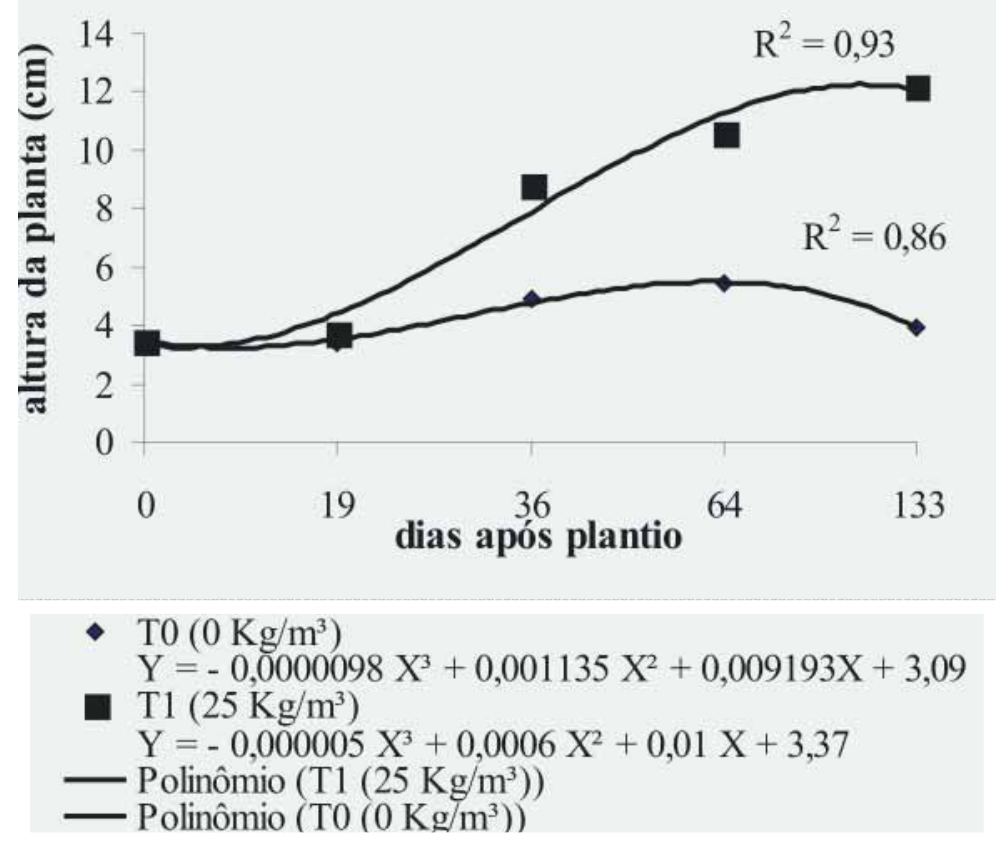




\section{GRÁFICO 2 - Altura das plantas de M elissa officinalis adubadas com 50, 75 e 100 kg de húmus/ $\mathrm{m}^{3}$ de substrato.}

Graph 2 -Height of Melissa officinalis fertilized with 50 and $75 \mathrm{~kg}$ of worm coprolite $/ \mathrm{m}^{3}$ of substratum.

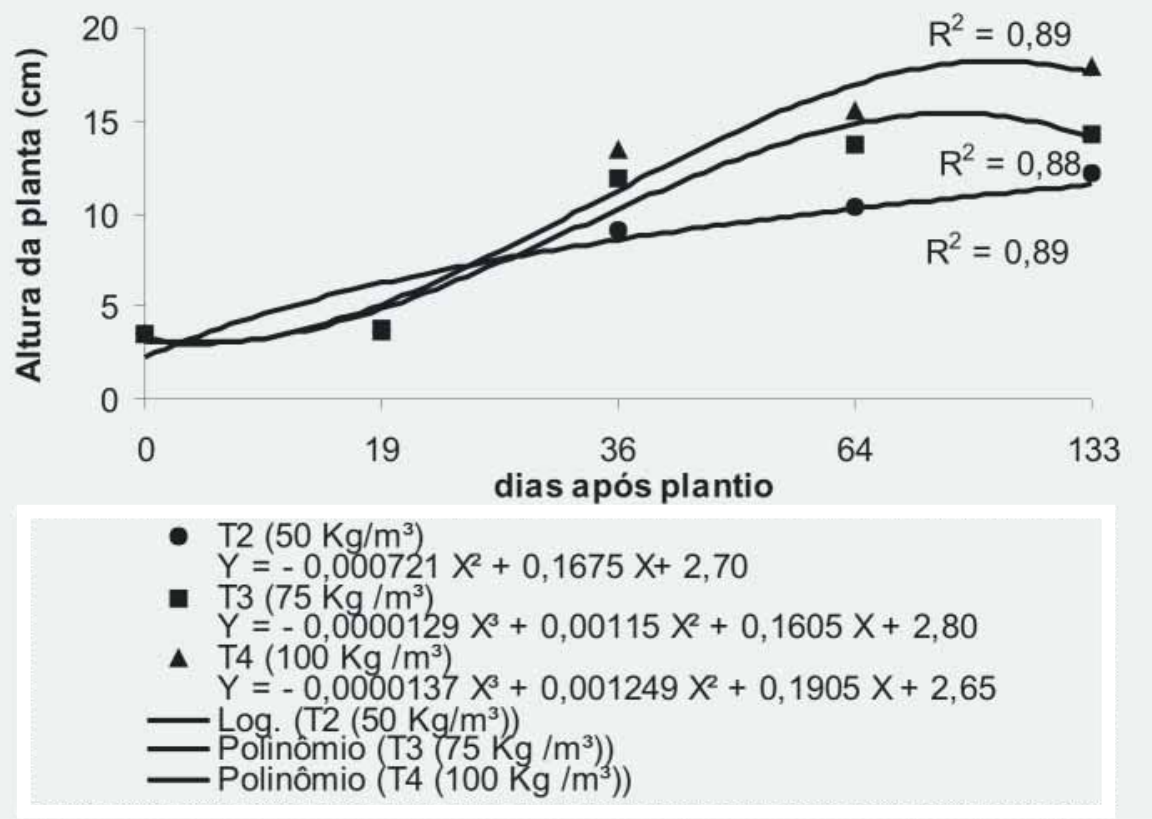

O modelo matemático que melhor ajustou-se aos dados de crescimento das plantas foi 0 polinômio de 3. grau (0, 25, 75 e 100 kg de húmus $/ \mathrm{m}^{3}$ de substrato) com um crescimento inicial lento até os 19 dias do plantio, seguido de um crescimento acelerado, em que aos 64 dias ocorreu maior pico de crescimento e após os 64 dias as plantas tenderam novamente a apresentar um crescimento lento.

O modelo polinomial de $2 .^{\circ}$ grau ajustou-se aos dados de crescimento do tratamento de $50 \mathrm{~kg}$ de húmus $/ \mathrm{m}^{3}$ de substrato, demonstrando que as plantas apresentaram uma curva crescente aos 19, 36, 64 e 133 dias após plantio, no que se refere à altura das plantas.

Os resultados obtidos no presente experimento indicam que as plantas apresentaram um crescimento inicial lento até 19 dias, em seguida atingem uma rápida resposta à adubação (19 a 64 dias) e voltam a apresentar um crescimento lento em altura após 64 dias do plantio. Dessa forma pode-se concluir que esse crescimento é o limite para a espécie em questão, porém, ao mesmo tempo em que as plantas atingiam o limite na altura, se ramificavam para os lados, apresentando maior volume em massa. A altura máxima atingida pelas plantas no presente experimento foi de $18,7 \mathrm{~cm}$.
A análise de regressão demonstrou haver influência sobre o crescimento no sentido de melhora com a utilização do húmus de minhoca com o decorrer dos dias após o plantio. Isto vem confirmar o que relataram Lopes; Guilherme (1990), que o adubo orgânico exerce efeitos promotores de crescimento das plantas.

Verificou-se que houve um aumento significativo na biomassa de Melissa officinalis em função dos tratamentos aplicados. Esses resultados são compatíveis com os obtidos por Scheffer (1998), que testou a influência da adubação orgânica sobre a biomassa, o rendimento e a composição do óleo essencial de Achillea millefolium L.

Os resultados obtidos na colheita permitiram avaliar o incremento de biomassa foliar, quando incorporados diferentes níveis de adubo orgânico.

De acordo com os dados avaliados estatisticamente, há diferenças expressivas com relação à massa das matérias fresca e seca das plantas com os diferentes níveis de adubo orgânico.

As massas fresca e seca da parte aérea total apresentaram as melhores respostas de rendimento nos tratamentos que receberam maiores níveis de húmus de minhoca, sendo o nível 100 $\mathrm{kg}$ de húmus/ $\mathrm{m}^{3}$ de substrato o mais adequado (GRÁFICO 4). 
O gráfico 3 mostra a massa seca das plantas da parte aérea total com umidade corrigida a
$12 \%$. Por esse gráfico, concluiu-se que quanto maior o nível de húmus, melhor o rendimento de massa por planta.

GRÁFICO 3 - Massa seca da parte aérea total de M elissa officinalis com umidade corrigida a 12\%, simulando a massa seca do material comercializado em diferentes níveis de húmus de minhoca. Graph 3 - Total dry matter of Melissa officinalis aerial part with corrected humidity at 12\%, simulating the dry matter of the commercialized material in different levels of worm coprolite.

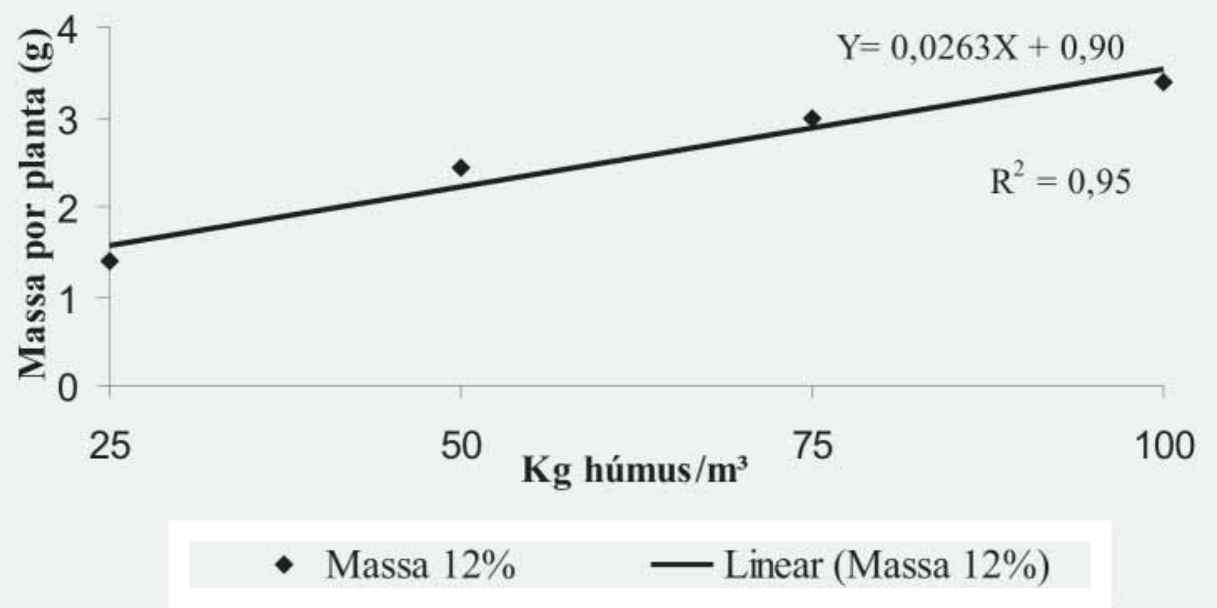

GRÁFICO 4 - Massas fresca e seca da parte aérea total de M elissa officinalis em diferentes níveis de húmus de minhoca.

Graph 4- Fresh and dry matter of Melissa officinalis total aerial partin differentlevelsof worm coprolite.

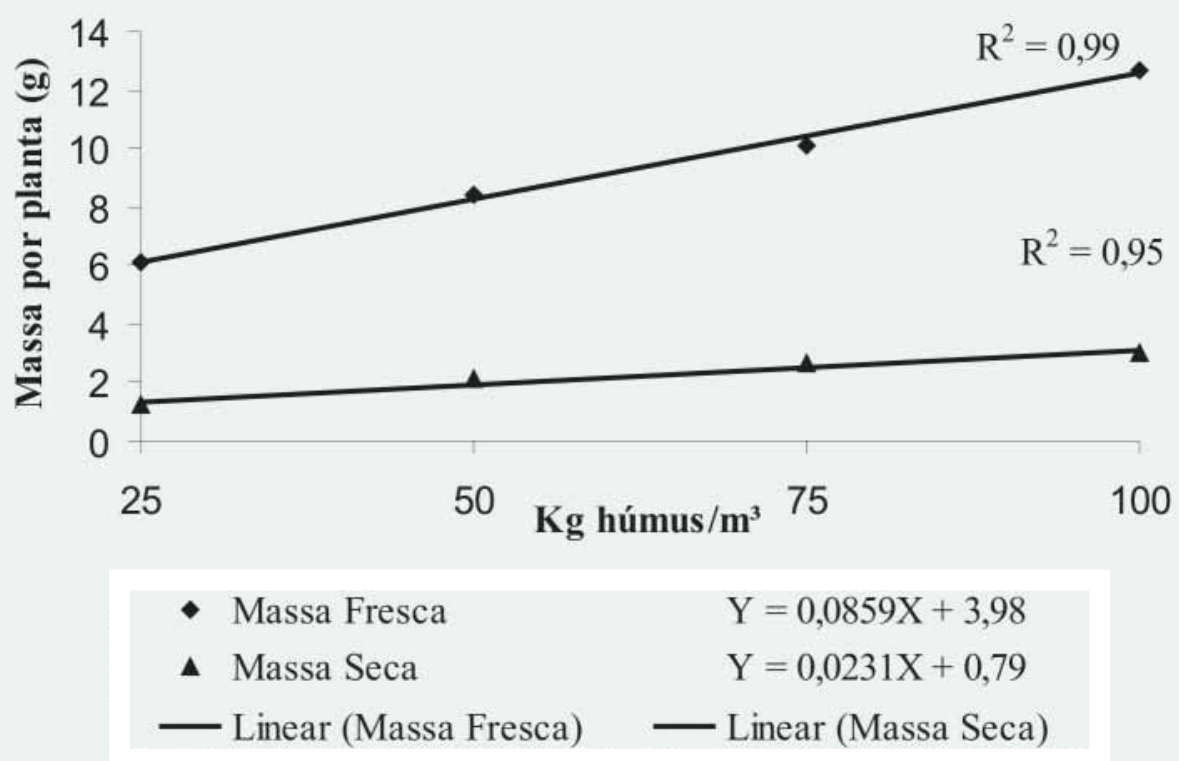


Os diferentes níveis de adubação orgânica, quando comparados com a testemunha, apresentaram as melhores respostas no que diz respeito à parte colhida das plantas, sendo o nível mais adequado $100 \mathrm{~kg}$ de húmus/ $\mathrm{m}^{3}$ de substrato.
O gráfico 5 mostra a massa seca das plantas com umidade corrigida a $12 \%$, sendo os resultados obtidos semelhantes aos da parte aérea total.

GRÁFICO 5 - Massa seca da parte colhida de Melissa officinalis com umidade corrigida a $12 \%$, simulando a massa seca do material comercializado em diferentes níveis de húmus de minhoca. Graph 5 - Dry matter of the Melissa officinalis harvested part with corrected humidity 12\%, simulating the dry matter of the commercialized material in different levels of worm coprolite.

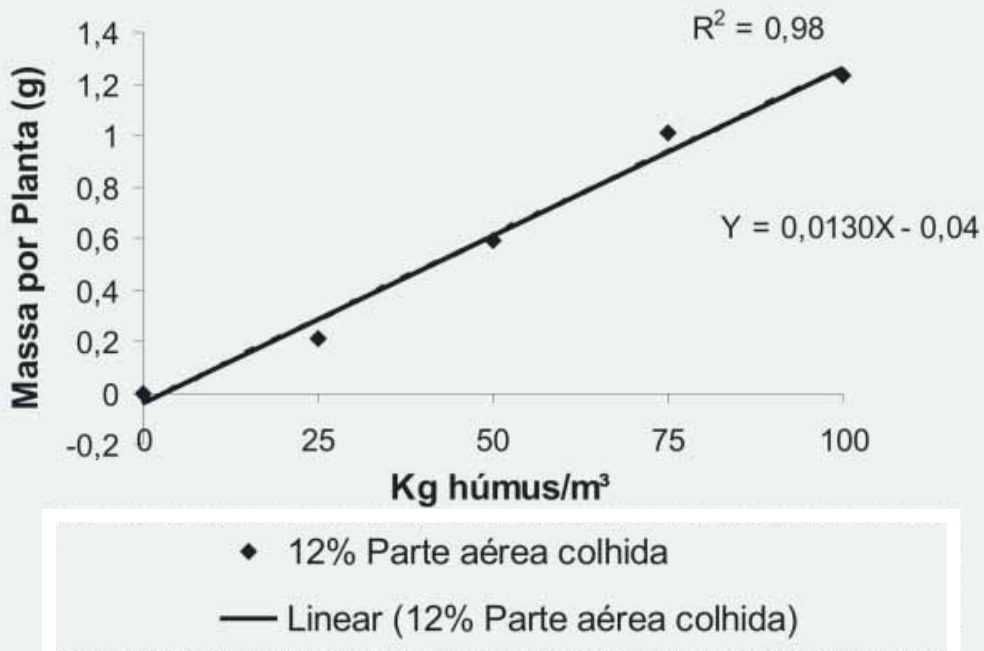

A análise de regressão evidenciou efeito linear no que se refere às massas fresca e seca das plantas, tanto na parte aérea total como na parte colhida, designando que há melhores resultados no rendimento para os tratamentos que receberam maiores níveis de adubação orgânica, sendo o nível estimado $100 \mathrm{~kg}$ de húmus $/ \mathrm{m}^{3}$ de substrato o mais indicado (GRÁFICO 6).

\section{GRÁFICO 6 - Massas fresca e seca da parte colhida de Melissa officinalis em diferentes níveis de húmus de minhoca.}

Graph 6 - Fresh and dry matter of the Melissa officinalis harvested part in differentlevels of worm coprolite.

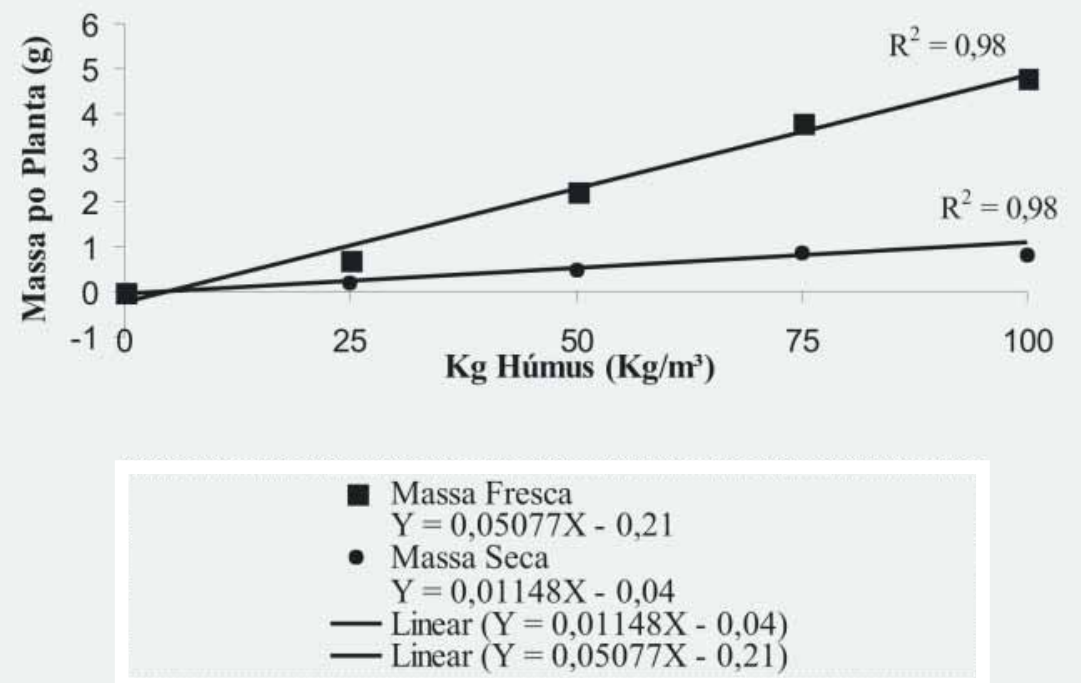


Segundo os dados do gráfico 7, concluiuse que quanto maior o nível de adubo, maior é a porcentagem de planta colhida. Essa afirmação é compatível com as observações feitas por Ming
(1992) que, trabalhando com Lippia alba (ervacidreira brasileira), demonstrou que quanto maior o nível de adubo orgânico, maior é a biomassa produzida.

\section{GRÁFICO 7 - Porcentagem de planta colhida de M el issa officinalisem diferentes níveis de húmus} de minhoca.

Graph 7 - Percentage of Melissa officinalis plant harvested in different levels of worm coprolite.

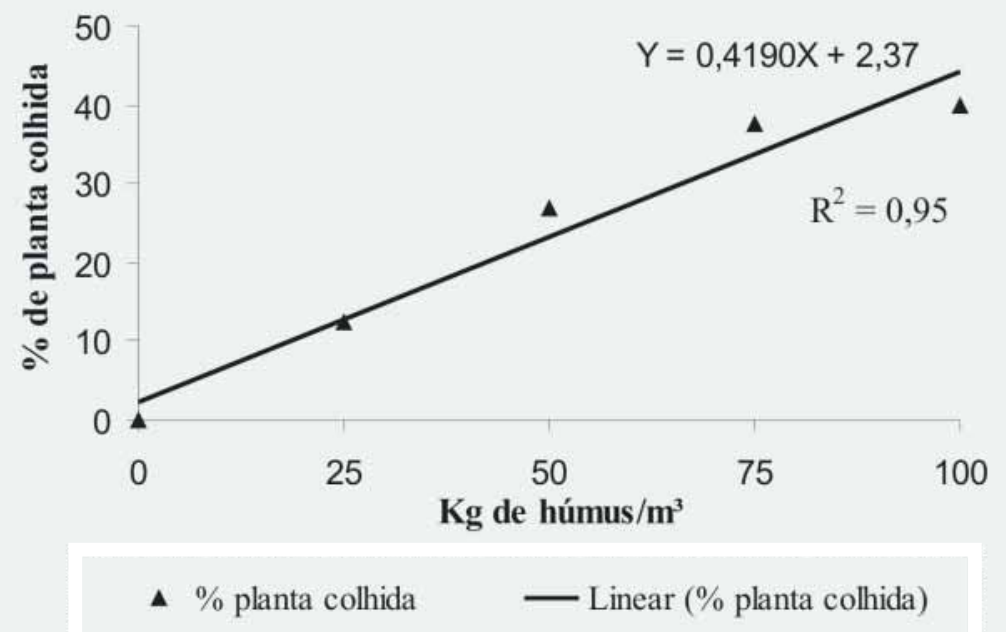

O gráfico 8 mostra o ajuste de uma função do 3. grau, por meio da análise de regressão, sobre a altura média das plantas aos 133 dias após o plantio em diferentes níveis do adubo orgânico, apresentando inicialmente uma rá- pida resposta à adubação e se estabilizando com os níveis de adubação 25, 50 e $75 \mathrm{~kg} / \mathrm{m}^{3}$ de substrato. Posteriormente com o nível de $100 \mathrm{~kg}$ de húmus $/ \mathrm{m}^{3}$ de substrato a resposta volta a ser maior.

\section{GRÁFICO 8 - Média da altura de M elissa officinal is em diferentes níveis de húmus de minhoca aos 133 dias após o plantio.}

Graph 8 - Height average of Melissa officinalis in different levels of worm coprolite at 133 daysafter the plantation.

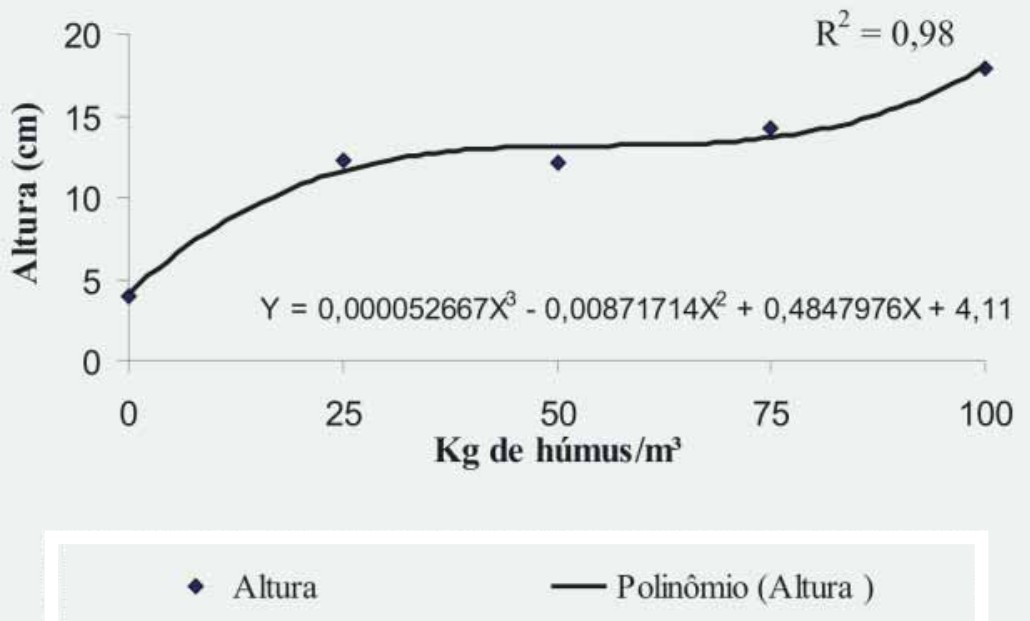


A análise de solo mostrou que houve uma pequena variação no pH do solo devido aos tratamentos, conforme pode ser observado na tabela 1. Foi observado que houve um pe- queno decréscimo de alumínio com a adição do húmus de minhoca. Houve aumento nos teores de Ca e Mg disponíveis no solo adubado com o húmus.

\section{TABELA 1 - Resultado da análise de solo dos cinco tratamentos, realizada no Laboratório de Análises Químicas de Solo, da Pontifícia Universidade Católica do Paraná.}

Table 1 - Soil analysis result of the five treatments, carried out in the Soil Chemical Analyses Laboratory, in the Pontifical Catholic University of Parana.

\begin{tabular}{l|l|l|l|l|l|l|l|l}
\hline $\begin{array}{l}\text { Húmus } \\
\mathbf{K g} / \mathbf{m}^{3}\end{array}$ & $\mathbf{A l}$ & $\mathbf{H}+\mathbf{A l}$ & $\begin{array}{l}\mathbf{C a} \\
\mathbf{c m o l} / \mathbf{d m}^{3}\end{array}$ & $\begin{array}{l}\mathbf{C a}+\mathbf{M g} \\
\mathbf{p p m}\end{array}$ & $\begin{array}{l}\mathbf{P} \\
\mathbf{p p m}\end{array}$ & $\begin{array}{l}\mathbf{K} \\
\mathbf{m g} / \mathbf{d m}^{3}\end{array}$ & $\mathbf{C}$ & $\mathbf{p H}$ \\
\hline 0 & 1,8 & 13,5 & 3,5 & 4,8 & 1,3 & 0,1022 & 59,47 & 4,05 \\
25 & 0,8 & 11,5 & 4,2 & 6,9 & 3,8 & 0,1048 & 49,41 & 4,25 \\
50 & 1,2 & 12,8 & 4,2 & 5,9 & 6,5 & 0,0990 & 49,13 & 4,15 \\
75 & 0,9 & 12,1 & 5,1 & 8,0 & 6,3 & 0,1200 & 46,87 & 4,32 \\
100 & 0,9 & 9,8 & 5,2 & 7 & 8,3 & 0,125 & 47,84 & 4,34 \\
\hline
\end{tabular}

Observou-se que houve um aumento muito expressivo no nível de fósforo. Alguns autores relatam a importância da adubação orgânica como fonte de fósforo disponível para as plantas (PAVAN et al., 1986; PEIXOTO et al., 1987).

Observa-se na tabela 1 que não houve efeito da adubação orgânica sobre a disponibilidade do potássio. Este resultado é compatível com as observações feitas por (SCHEFFER, 1998).

Houve influência do húmus de minhoca sobre a disponibilidade de carbono no solo, apresentando um decréscimo com os tratamentos (25, $50,75,100 \mathrm{~kg} / \mathrm{m}^{3}$ de substrato) em relação ao tratamento testemunha. Embora não encontrado na literatura, este fato pode ser explicado devido às condições do meio apresentadas pela casa de vegetação. Contudo, essa informação poderá servir para futuros estudos.

Não se pode fazer recomendações para adubação orgânica apenas levando-se em consideração a produção de biomassa e altura média das plantas. Em se tratando de plantas medicinais, deve-se também levar em conta os princípios ativos contidos nelas. Consideram-se também outros aspectos técnicos e econômicos, como, por exemplo, o custo do $\mathrm{m}^{3}$ do adubo orgânico e a sua disponibilidade.

De acordo com os resultados obtidos foi possível concluir que a utilização do adubo orgânico no cultivo de melissa em casa de vegetação tem influência no crescimento e no desenvolvimento das plantas, porém, mais estudos devem ser realizados no sentido de se verificar a viabilidade do seu uso.

As análises dos dados resultantes deste experimento são pontos de partida para outros trabalhos que podem e devem ser feitos para a determinação de mais informações técnicas sobre a Melissa officinalis, entretanto seu cultivo em casa de vegetação fora de época foi viável para os tratamentos que receberam diferentes níveis de adubação orgânica com o húmus de minhoca.

\section{Conclusões}

$\mathrm{O}$ incremento em altura das plantas e em biomassa foliar foi significativo, quando incorporados diferentes níveis de adubo orgânico. 
No que se refere à altura, concluiu-se que as plantas apresentam um crescimento inicial lento até os 19 dias do plantio, em seguida atingem uma rápida resposta à adubação (19 - 64 dias) e voltam a apresentar um crescimento lento 64 dias após o plantio.

No que diz respeito às massas fresca e seca das plantas, tanto na parte aérea total, como na parte colhida, os melhores resultados foram os que receberam o maior nível de adubação orgânica (100 kg de húmus/ $\mathrm{m}^{3}$ de substrato).

As diferenças significativas entre os tratamentos com relação à altura das plantas permitem sugerir a utilização do maior nível testado, ou seja, $100 \mathrm{~kg}$ de húmus/ $\mathrm{m}^{3}$ de substrato.

\section{Referências}

CANALVIP. Melissa officinalis - Melissa. Disponível em: <http:// www.canalvip.com.br/ neumart/ pm/melioffl.htm>Acesso em 01 de março de 2002.

CASTRO, L. O .; CHEMALE, V. M. Plantas medicinais, condimentares e aromáticas: descrição e cultivo. Guaíba: Agropecuária, 1995.

CORREA JUNIOR, C.; MING, L. C.; SCHEFFER, M. C. Cultivo de plantas medicinais, condimentares e aromáticas. Curitiba: EMATER-PR, 1994.

CORREA JUNIOR,C. Influência das adubações orgânica e química na produção de camomila Chamomilla recutita (L) Rauschert e do seu óleo essencial. In: MING, L C. (Coord) et al. Plantas medicinais, aromáticas e condimentares: avanços da pesquisa agronômica. Botucatu: UNESP. 1998. v.1. p. 165-191.

GEOCITIES. Erva-cidreira. Disponível em: <http:/ /br.geocities.com/ervas_dilenemaia/reino_vegetal/ perfumes/reino_veg.../erva_cidreira.ht http:// br.geocities.com/ervas_dilenemaia/reino_vegetal/ perfumes/reino_veg.../erva_cidreira.ht>Acesso em: 21 fev. 2002a.

O que é importante saber sobre o húmus de minhoca. Disponível em: <http:// www.geocities.com/siliconvalley/ hub/2467/ humus/htm > Acesso em: 14 mar. 2002b.
HAWORTH, F., CLEAVER, T. J. The effects of different treatments on the yield and mineral composition of winter lettuce. J. Hortic. Sci. v. 42, p. 23-29, 1967.

HORTA EM CASA. Melissa (Erva Cidreira). Disponível em: 〈http://www.hortaemcasa.com.br/produtos/melissa.htm> Acesso em: 01 mar. 2002.

LOPES, T. F. et al. Estudo em cromatógrafo de óleo essenciais extraídos de vegetais da região de Araraquara. Fac. Farm. Odont. Araraquara, v. 9, n. 2, p. 199-208, 1975.

LOPES, A. S.; GUILHERME, L. R. G. Uso eficiente de fertilizantes. São Paulo, SP: ANDA, 1990. 51 p. (Boletim técnico, 4).

MING, L. C. Influência dos diferentes níveis de adubação orgânica na produção de biomassa e teor de óleo essencial de Lippia alba. 1992. 206 f. Dissertação (Mestrado) - UFPR, Curitiba: 1992.

PAVAN, M. A. et al. Manejo da cobertura do solo para formação e produção de uma lavoura cafeeira. Pesquisa Agropecuária Brasileira, Brasília, v. 21, n. 2, p. 187-192, 1986.

PEIXOTO, R. T. G.; FRANCO, A. A.; ALMEIDA, D. L. Efeito do lixo urbano compostado com fosfato natural na nodulação, crescimento e absorção de fósforo em feijoeiro. Pesquisa Agropecuária Brasileira, Brasília, v. 22, n. 11/12, p. 1117-1132, 1987.

PEREIRA, J. E. Minhocas: manual prático sobre minhocultura. São Paulo, SP: Nobel, 1997.

PRIMAVESI, O. Fatores limitantes da produtividade agrícola e plantio direto. São Paulo, SP: BASF, 1982.

SCHARNIK, M. Cultivo orgânico da melissa. Curitiba, 2001. p. 1-9. (Boletim técnico 001/01).

SCHEFFER, M. C. Influência da adubação orgânica sobre a biomassa, o rendimento e a composição do óleo essencial de Achillea millefolium L - Milfolhas. In: MING, L C. (Coord.) et al. Plantas medicinais, aromáticas e condimentares: avanços da pesquisa agronômica. Botucatu: UNESP. 1998. v. 1. p. 1-22.

Recebido: 17/02/2005 Aprovado: 30/06/2005 